\title{
Associação entre as lesões renais microscópicas e a presença de anticorpos contra Leptospira spp em suínos aparentemente sadios, abatidos em frigorífico da região norte do estado do Paraná
}

\section{Association between microscopic kidney's lesions and presence of antibodies against Leptospira spp in apparently healthy swine, originated from slaughterhouse in northern Paraná state}

\author{
Vanessa Yumi Hashimoto; ${ }^{1}$ Eleine Kuroki Anzai ${ }^{1}$; Bruna Azevedo de Carvalho \\ Lima $^{1}$; Francielle Gibson da Silva ${ }^{1}$; Lucimara Aparecida Alves ${ }^{1}$; \\ Roberta Lemos Freire²; Paulo Sérgio Teles ${ }^{3}$; João Luís Garcia ${ }^{2}$; \\ Ernst Eckehardt Müller²; Júlio César de Freitas ${ }^{4 *}$
}

\begin{abstract}
Resumo
O objetivo deste trabalho foi demonstrar a associação entre lesões renais microscópicas e a presença de anticorpos contra Leptospira spp em suínos aparentemente sadios, abatidos em frigorífico da região norte do Estado do Paraná. Foram colhidas amostras de rim e coágulo sanguíneo de 120 animais com lesões renais macroscópicas tipo white spots e de 120 sem lesões renais macroscópicas tipo white spots, utilizados como controle. As amostras de soro foram submetidas à prova de soroaglutinação microscópica (SAM) e as amostras de rim, ao exame histopatológico corado pela Hematoxilina-Eosina (HE). Embora nenhuma associação $(\mathrm{p}=0,27)$ entre as lesões renais macroscópicas tipo white spots e a presença de anticorpos contra Leptospira spp tenha sido observada, verificou-se uma significativa associação $(\mathrm{p}=0,015)$ entre a nefrite intersticial e a soropositividade para leptospirose.

Palavras-chave: Leptospirose, rim, lesão white spots, sorologia, histopatologia
\end{abstract}

\begin{abstract}
The aim of this work was to demonstrate the association between microscopic kidney's lesions and presence of antibodies against Leptospira spp in apparently healthy swine from slaughterhouses located in northern Paraná State. Samples of kidney and blood coagulum were collected from 120 animals with macroscopic kidney's lesions type white spots and from 120 animals without macroscopic lesions, used as control. Samples of serum, were submitted to microscopic agglutination test (MAT) and samples of kidney for histopathological evaluation stained with Hematoxylin and Eosin (HE). Although no association $(\mathrm{p}=0,27)$ between macroscopic kidney's lesions type white spots and presence of antibodies against Leptospira spp has been observed, there was a significant association $(\mathrm{p}=0,015)$ between interstitial nephritis and seropositivity to leptospirosis.
\end{abstract}

Key words: Leptospirosis, kidney, lesion white spots, serology, histopathology

\footnotetext{
Aluna do Programa de Pós-graduação em Ciência Animal, Departamento de Medicina Veterinária Preventiva, Centro de Ciências Agrárias, Universidade Estadual de Londrina.

2 Professor do Departamento de Medicina Veterinária Preventiva, Centro de Ciências Agrárias, Universidade Estadual de Londrina.

3 Médico Veterinário do Serviço de Inspeção Federal.

4 Professor do Departamento de Medicina Veterinária Preventiva, Centro de Ciências Agrárias, Universidade Estadual de Londrina. E-mail: freitasj@uel.br.

* Autor para correspondência
} 


\section{Introdução}

Apesar da leptospirose em suínos ser reconhecida mundialmente pelos transtornos na esfera reprodutiva (OLIVEIRA, 1994), estes animais quando infectados por leptospiras durante a fase de terminação são considerados freqüentemente como portadores sãos e quando levados ao abate, podem passar despercebidos pelo Serviço de Inspeção Veterinária (ELLIS, 1999).

Leptospira spp se caracteriza pela persistência nos rins sendo eliminada pela urina por vários meses após a infecção (FAINE, 1982), assumindo importância em saúde pública. As alterações histológicas em rins infectados por leptospiras mostram um quadro variado de lesões, predominando as nefrites intersticiais. As lesões macroscópicas da nefrite intersticial, conhecidascomo whitespots apresentamse como focos branco-acinzentados de um a três milímetros de diâmetro, predominantemente corticais (OLIVEIRA,1988) e segundo Drolet et al (2002) estas lesões são consideradas uma das principais causas de condenação de rins de suínos em frigoríficos. Vários estudos têm sido realizados para esclarecer a etiologia da nefrite intersticial em suínos, aparentemente sadios, abatidos em frigorífico (HUNTER et al., 1987; BAKER et al., 1989; DROLET et al.; 2002; BOQVIST et al., 2003). Entre os vários microrganismos responsáveis pela nefrite intersticial em suínos, a Leptospira spp tem sido apontada como um dos principais agentes causadores destas lesões (JONES et al., 1987). As alterações decorrentes da presença das leptospiras em tecidos de eleição do agente como os rins, podem ser visualizadas pelo exame histopatológico corado pelo HE. Entre as várias provas de diagnóstico da leptospirose suína, a soroaglutinação microscópica (SAM) é método mais utilizado mundialmente e recomendado pela Organização Mundial de Saúde (FAINE et al., 1999). O objetivo deste trabalho foi demonstrar a associação entre as lesões renais microscópicas e a presença de anticorpos contra Leptospira spp em suínos aparentemente sadios, abatidos em frigorífico com Serviço de Inspeção Federal da região norte do Estado do Paraná.

\section{Material e Métodos}

Durante o período de março de 2004 a abril de 2005, foram obtidos materiais biológicos de 240 suínos, aparentemente sadios, com histórico sanitário desconhecido, oriundos de várias propriedades, abatidos em frigorífico com Serviço de Inspeção Federal da região norte do Estado do Paraná. Foram colhidas amostras de rim e coágulo sanguíneo de 120 animais com lesões renais macroscópicas tipo white spots e de 120 sem lesões renais macroscópicas tipo white spots, utilizados como controle. As visitas ao frigorífico foram realizadas semanalmente, quando eram colhidas até 10 amostras, dependendo da casualidade das lesões.

As amostras de coágulos sanguíneos, obtidas após a colheita dos respectivos rins, durante a linha de abate, foram acondicionadas imediatamente em frascos estéreis e identificados com o número da carcaça. Os frascos foram mantidos em temperatura ambiente e após a obtenção do soro, divididos em duas alíquotas e armazenados a $-20^{\circ} \mathrm{C}$ até o momento de sua utilização. Para detectar anticorpos contra Leptospira spp, os 240 soros foram submetidos a SAM, utilizando 22 sorovares de referência: Australis, Bratislava, Autumnalis, Butembo, Castellonis, Bataviae, Canicola, Whitcomb, Cynopteri, Fortbragg, Grippotyphosa, Hebdomadis, Copenhageni, Icterohaemorrhagiae, Panama, Pomona, Pyrogenes, Hardjo, Wolffi, Shermani, Sentot e Tarassovi. Todos os sorovares de referência foram mantidos a $28^{\circ} \mathrm{C}$ por 5 a 10 dias em meio EMJH (DIFCOß-USA) modificado pela adição de soro de coelho (ALVES, 1995).

Os soros foram inicialmente diluídos a 1:50 em tampão PBS. Alíquotas de $50 \mu 1$ de cada soro foram pipetadas em cavidades de microplacas acrescentando-se a seguir $50 \mu 1$ de cada um dos antígenos nas cavidades correspondentes a cada 
amostra, obtendo-se assim, a diluição final de 1:100. Os soros reagentes na triagem foram titulados em uma série de diluições geométricas de razão dois. O título do soro foi a recíproca da maior diluição que apresentou 50\% de leptospiras aglutinadas (FAINE et al., 1999). A leitura foi realizada pela microscopia de campo escuro de acordo com Myers (1985). A análise dos resultados considerou como mais provável o sorovar que apresentou o maior título.

As amostras de rim obtidas de cada animal, na linha de abate, foram acondicionadas imediatamente sob refrigeração em caixas térmicas por no máximo três horas. Fragmentos de áreas com lesão tipo white spots (caso) e fragmentos aparentemente normais (controle), foram fixados em solução de formalina tamponada a $10 \%$ e submetidos à desidratação em soluções crescentes de álcoois, diafanização em xilol e inclusão em parafina. De cada fragmento foram realizados cortes de $5 \mu \mathrm{m}$ de espessura. Estes cortes foram submetidos à coloração de HE para o diagnóstico histopatológico (BREHMER, 1976).

A associação entre os suínos reagentes na SAM e as alterações renais macroscópicas e microscópicas foi analisada através do Teste do Qui-Quadrado $\left(\chi^{2}\right)$ ou Exato de Fisher utilizando o programa estatístico
EpiInfo, versão 6.04d (CDC-Atlanta), adotando-se como significativo um $\mathrm{p} \leq 0,05$.

\section{Resultados e Discussão}

Dos 240 soros utilizados, 35 (14,58\%) foram reagentes na SAM com títulos de anticorpos $\geq 100$, sendo 21 white spots positivos e 14 white spots negativos (Tabela 1). Em 23 (65,71\%) soros, foram detectados anticorpos contra o sorovar Icterohaemorrhagiae. Resultados semelhantes foram obtidos por Delben et al. (2002) que encontraram uma maior freqüência $(79,16 \%)$ de anticorpos contra o sorovar Icterohaemorrhagiae em suínos destinados ao abate no norte do Paraná. De acordo com Faine (1982), os roedores sinantrópicos são considerados os principais reservatórios do sorovar Icterohaemorrhagiae. Fávero et al. (2002) sugerem que a evolução da suinocultura nacional, observada nos últimos anos, deve ter modificado o perfil sorológico das granjas, causando a substituição do sorovar Pomona, tradicionalmente mantido pelos próprios suínos, pelo sorovar Icterohaemorrhagiae. Para Faine (1982) é necessário a implantação de procedimentos destinados ao controle dos roedores sinantrópicos como parte do manejo das criações.

Tabela 1. Resultados da prova de soroaglutinação microscópica (SAM) em 240 suínos, aparentemente sadios, sendo 120 do grupo white spots positivo e 120 do grupo white spots negativo, abatidos em frigorífico com Serviço de Inspeção Federal da região norte do Estado do Paraná, 2004 a 2005.

\begin{tabular}{lllllll}
\multirow{2}{*}{ Lesão renal macroscópica } & \multicolumn{2}{c}{ Reagente* } & \multicolumn{2}{c}{ Não reagente } & \multicolumn{2}{c}{ Total } \\
\cline { 2 - 8 } & $\mathrm{n}^{\mathrm{o}}$ & $(\%)$ & $\mathrm{n}^{\mathrm{o}}$ & $(\%)$ & $\mathrm{n}^{\circ}$ & $(\%)$ \\
\hline white spots positivo & 21 & $(8,75)$ & 99 & $(41,25)$ & 120 & $(50,00)$ \\
white spots negativo & 14 & $(5,83)$ & 106 & $(44,17)$ & 120 & $(50,00)$ \\
\hline Total & 35 & $(14,58)$ & 205 & $(85,42)$ & 240 & $(100,00)$
\end{tabular}

* título $\geq 100 ; \mathrm{p}=0,27$ 
Neste trabalho, não foi demonstrada associação $(p=0,27)$ entre as lesões renais macroscópicas tipo white spots e a presença de anticorpos contra Leptospira spp nos animais estudados (Tabela 1). De acordo com Faine et al. (1999), o rim é considerado um dos principais locais de persistência de leptospiras em suínos e pode não apresentar lesão macroscópica quando infectado. Apesar de Hunter et al. (1987) e Baker et al. (1989) considerarem as lesões macroscópicas renais tipo white spots a única indicação de leptospirose em suínos, aparentemente sadios, abatidos em frigorífico, Chappel et al. (1992) demonstraram que nem todos os suínos infectados experimentalmente por Leptospira spp desenvolveram lesões white spots até três semanas pós infecção. Boqvist et al. (2003) não consideraram este tipo de lesão como um bom indicador da infecção por leptospiras, pois $62 \%$ dos rins de suínos white spots negativos apresentaram-se infectados quando submetidos a prova de imunofluorescência.

Nos rins de $120(100 \%)$ animais white spots positivos e nos rins de 84 (70\%) white spots negativos, foram encontradas alterações histológicas, caracterizadas como: infiltrados inflamatórios intersticiais de células linfocitárias e plasmocitárias, focais e difusas e focos de fibrose da porção cortical renal (Tabela 2). Os túbulos e glomérulos dos rins com as alterações teciduais estavam frequentemente distorcidos, espessados, caracterizando a nefrite intersticial. Os rins destes 204 animais apresentaram as mesmas alterações histológicas, diferenciadas somente quanto à intensidade dos infiltrados inflamatórios.

Tabela 2. Resultados dos exames histopatológicos corados por Hematoxilina-Eosina (HE) e prova de soroaglutinação microscópica (SAM) em 240 suínos, aparentemente sadios, sendo 120 do grupo white spots positivo e 120 do grupo white spots negativo, abatidos em frigorífico com Serviço de Inspeção Federal da região norte do Estado do Paraná, 2004 a 2005.

\begin{tabular}{|c|c|c|c|c|c|c|c|}
\hline \multirow{3}{*}{ Lesão renal macroscópica } & \multirow{3}{*}{ Histopatologia } & \multicolumn{6}{|c|}{ SAM } \\
\hline & & \multicolumn{2}{|c|}{ Reagente* } & \multicolumn{2}{|c|}{ Não reagente } & \multicolumn{2}{|c|}{ Total } \\
\hline & & $\mathrm{n}^{\mathrm{o}}$ & $(\%)$ & $\mathrm{n}^{\mathrm{o}}$ & $(\%)$ & $\mathrm{n}^{\mathrm{o}}$ & $(\%)$ \\
\hline \multirow{3}{*}{ white spots positivo } & $\mathrm{HE}+$ & 21 & $(17,50)$ & 99 & $(82,50)$ & 120 & $(100,00)$ \\
\hline & HE - & 0 & (0) & 0 & (0) & 0 & (0) \\
\hline & Total & 21 & $(17,50)$ & 99 & (0) & 120 & $(100,00)$ \\
\hline \multirow{3}{*}{ white spots negativo } & $\mathrm{HE}+$ & 14 & $(11,67)$ & 70 & $(58,33)$ & 84 & $(70,00)$ \\
\hline & HE - & 0 & (0) & 36 & $(30,00)$ & 36 & $(30,00)$ \\
\hline & Total & 14 & $(11,67)$ & 106 & $(88,33)$ & 120 & $(100,00)$ \\
\hline
\end{tabular}

* Título $\geq 100$ 
Nos rins dos $35(14,58 \%)$ animais reagentes na SAM, foram encontradas, alterações histológicas caracterizadas como nefrite intersticial. Estas alterações teciduais estão de acordo com Baker et al. (1989), que as descreveram em suínos reagentes para o sorovar Icterohaemorrhagiae. No presente estudo, foi encontrada associação $(p=0,015)$ entre a nefrite intersticial e a soropositividade na SAM (Tabela 3). Delben et al. (2002) também demonstraram uma relação entre suínos com títulos de anticorpos antileptospiras e a presença de alterações teciduais, compatíveis com a infecção por Leptospira spp. É provável que os 14 animais reagents na SAM, com nefrite intersticial, do grupo white spots negativo, tenham se infectado recentemente e estavam na fase aguda da infecção, concordando com Hunter et al (1987) que afirmaram que animais nesta fase da infecção apresentam alterações histológicas, como nefrite intersticial, sem as lesões white spots. A nefrite intersticial detectada nos demais animais não reagentes na SAM (99 white spots positivos e 70 white spots negativos) pode ter sido causada por outros microrganismos além da Leptospira spp como demonstrado por Drolet e Dee (1999) e por Martínez et al. (2005), que relacionaram esta lesão a outras etiologias.

Tabela 3. Associação dos exames histopatológicos corados pela Hematoxilina-Eosina com a prova de soroaglutinação microscópica (SAM) em 240 suínos, aparentemente sadios, abatidos em frigorífico com Serviço de Inspeção Federal da região norte do Estado do Paraná, 2004 a 2005.

\begin{tabular}{lllllll}
\multirow{2}{*}{ Histopatologia } & \multicolumn{2}{c}{ Reagente* } & \multicolumn{2}{c}{ Não reagente } & \multicolumn{2}{c}{ Total } \\
\cline { 2 - 7 } & $\mathrm{n}^{\mathrm{o}}$ & $(\%)$ & $\mathrm{n}^{\mathrm{o}}$ & $(\%)$ & $\mathrm{n}^{\text {o }}$ & $(\%)$ \\
\hline $\mathrm{HE}+$ & 35 & $(14,58)$ & 169 & $(70,42)$ & 204 & $(85,00)$ \\
$\mathrm{HE}-$ & 0 & $(0)$ & 36 & $(15,00)$ & 36 & $(15,00)$ \\
\hline \multirow{2}{*}{ Total } & 35 & $(14,58)$ & 205 & $(85,42)$ & 240 & $(100,00)$
\end{tabular}

* Título $\geq 100 ; p=0,015$

O presente trabalho demonstrou que a associação entre as lesões renais macroscópicas tipo white spots e a presença de anticorpos contra Leptospira spp nos suínos estudados não foi significativa. Porém, os animais com lesões de nefrite intersticial apresentaram associação com a soropositividade na SAM. Outro fator importante foi o fato de todos os animais que não apresentaram lesões de nefrite intersticial foram negativos na SAM.

\section{Agradecimentos}

À Coordenação de Aperfeiçoamento de Pessoal de Nível Superior (CAPES), pela concessão da bolsa de estudos.

\section{Referências}

ALVES, C. J. Influência de fatores ambientais sobre a proporção de caprinos sororreatores para leptospirose em cinco centros de criação do Estado da Paraíba, Brasil. 1995. Tese. (Doutorado) - Faculdade de Medicina Veterinária e Zootecnia da Universidade de São Paulo, São Paulo.

BREHMER, O. A. Manual de técnicas para histologia normal e patológica. São Paulo: EDART, 1976.

BAKER, T. F.; MCEWEN, S. A.; PRESCOTT, J. F.; MEEK, A. H. The prevalence of leptospirosis and its association with multifocal interstitial nephritis in swine at slaughter. Canadian Journal of Veterinary Research, Ottawa, v. 53, n. 3, p. 290-294, 1989.

BOQVIST, S.; MONTGOMERY, J. M.; HURST, M.; HO THI VIET THU, E.; ENGVALL, A. O.; GUNASSON, A.; MAGNUSSON, U. Leptospira in slaughtered fattening 
pigs in southern Vietnam: presence of bacteria in the kidneys and association with morphological findings. Veterinary Microbiology, Amsterdam, v. 93, n. 4, p. 361368, 2003.

CHAPPEL, R. J.; ELLIA, W. A.; ADLER, B.; AMON, L.; MILLAR, B. D.; ZHU, S. S.; PRIME, R. W. Serological evidence for the presence of Leptospira interrogans serovar bratislava in Australian pigs. Australian Veterinary Journal, Brunswick, v. 69, n. 5, p. 119-120, 1992.

DELBEN, A. C. B.; BRACARENSE, A. P. F. R. L.; MÜLLER, E. E.; OLIVEIRA, R. C. Leptospirosis in slaughtered sows: serological and histopathological investigation. Brazilian Journal of Microbiology, São Paulo, v. 33, n. 2, p. 174-177, 2002.

DROLET, R.; DEE, S. A. Diseases of the urinary system. In: STRAW, B. E.; D'ALLAIRE, S. D.; MENGELING, W. L.; TAYLOR, D. J. Diseases of swine. Ames: The Iowa State University Press, 1999. p. 966-967.

DROLET, R.; RIBOTTA, M.; HIGGINS, R.; D'AllAire, R.; LAROCHELlE, S.; MAGAR, R. Infectious agents identified in pigs with multifocal interstitial nephritis at slaughter. The Veterinary Record, London, v. 150, n. 5, p. 139-143, 2002.

ELLIS, W. A. Leptospirosis. In: . Disease of swine. Ames: The Iowa State University Press, 1999. p. 483-493.

FAINE, S. Guidelines for the control of leptospirosis. Geneva: World Health Organization, 1982. (WHO Offset Publication, 67).

FAINE, S.; ADLER, B.; BOLIN, C.; PEROLAT, P. Leptospira and leptospirosis. Melbourne: Medical Science, 1999.
FÁVERO,A.C.M.;PINHEIRO,S.R.;VASCONCELLOS, A. S.; MORAIS, Z. M.; FERREIRA, F.; FERREIRA NETO, J. S. Sorovares de Leptospiras predominantes em exames sorológicos de bubalinos, ovinos, caprinos, eqüinos, suínos e cães de diversos estados brasileiros. Ciência Rural, Santa Maria, v. 32, n. 4, p. 613-619, 2002.

HUNTER, P.; VAN DER VYVER, F. H.; SELMEROLSEN, A.; HENTON, M. M.; HERR, S.; DE LANGE, J. F. Leptospirosis as a cause of "white spot" kidneys in South African pig abattoirs. Onderstepoort Journal of Veterinary Research, South Africa, v. 54, n. 1, p. 59-62, 1987.

JONES, R. T.; MILLAR, B. D.; CHAPPEL, R. J.; ADLER, B. Macroscopic kidney lesions in slaughtered pigs are an inadequate indicator of current leptospiral infection. Australian Veterinary Journal, Brunswick, v. 64, n. 8, p. 258-259, 1987.

MARTÍNEZ, J.; SEGALÉS, J.; ADUREZ, G.; ATXAERANDIO, R.; JARO, P.; ORTEGA, J.; PERES, B.; CORPA, J. M. Pathological and aetiological studies of multifocal interstitial nephritis in wasted pigs at slaughter. Research in Veterinary Science, London, v. 81, n. 1, p. 92-98, 2005.

MYERS, D. Leptospirosis: Manual de métodos para el diagnóstico de laboratório. Buenos Aires: Centro Panamericano de Zoonosis/OPS/OMS, 1985.

OLIVEIRA, S. J. Infecções no trato urinário em suínos. Boletim do Instituto de Pesquisas Veterinárias Desidério Finamor, Guaiba, v. 1, n. 130, p. 71-85, 1988.

. Atualização nos conceitos sobre leptospirose em suínos. A Hora Veterinária, Rio Grande do Sul, v. 79, n. 1, p. 52-55, 1994. 